Research Article

\title{
Design Method for Specific Charge in Deep Mining considering Influence of In Situ Stress
}

\author{
Fengpeng Zhang $\mathbb{D}^{1},{ }^{1}$ Qiqi Hao $\mathbb{D}{ }^{1}{ }^{1}$ Xiulong Wang $\mathbb{D},{ }^{1}$ and Zhaoguo Qiu $\mathbb{D}^{2}$ \\ ${ }^{1}$ Key Laboratory of Ministry of Education on Safe Mining of Deep Metal Mines, Northeastern University, \\ Shenyang 110819, China \\ ${ }^{2}$ School of Science, Northeastern University, Shenyang 110819, China
}

Correspondence should be addressed to Qiqi Hao; neuhaoqiqi@163.com

Received 10 July 2020; Revised 1 August 2021; Accepted 8 August 2021; Published 20 August 2021

Academic Editor: Valeria Vignali

Copyright (c) 2021 Fengpeng Zhang et al. This is an open access article distributed under the Creative Commons Attribution License, which permits unrestricted use, distribution, and reproduction in any medium, provided the original work is properly cited.

\begin{abstract}
In situ stress has a large influence on blasts in deep mines and should be considered in blasting design. In this study, explosion crater tests were conducted to investigate the variation of specific charges under different stress loading conditions. It was revealed that rock blasting under high stress is different from that under low stress. A correction coefficient for specific charge was defined to consider the influence of in situ stress on blasting. A quantitative relation between the correction coefficient, stress-to-strength ratio, and lateral stress coefficient was presented. Based on the explosion-crater test results, a design method for specific charges was proposed with the consideration of in situ stress. Finally, the design method was applied to a field blasting test at Hongtoushan Copper Mine. The test results indicate that the proposed design method can effectively use the high in situ stress at depth for rock fragmentation. Compared with the original blasting design, the specific charge is reduced by $19.8 \%$ and the average block rate is reduced from $6.8 \%$ to $2.84 \%$. At the same time, the blasting boundary is well controlled and the ore loss and dilution rates are reduced. This research has important guiding significance to deep mine blasting design.
\end{abstract}

\section{Introduction}

With the decrease of shallow mineral resources, the exploitation of deep mineral resources has gradually become the trend in mining. The mining depth of the deepest mine in the world has extended to nearly $4000 \mathrm{~m}$ below the Earth's surface [1]. An important issue in deep engineering projects is the high in situ stress field [2-5]. The drill-and-blast method is one of the main methods of rock fragmentation [6-9]. When the drill-and-blast excavation method is used in excavation of deep mineral resources, rocks are fragmented under the coupled effect of high static stress and blastinginduced dynamic stress [8-12]. The in situ stress plays a large role in affecting efficiency and quality of blasting, which should be considered in blast design.

Many investigations on the effects of field stress on rock blasting have been carried out. Kutter and Fairhurst [8] found that blasting-induced cracks propagate preferably in the direction of the applied static stress. Similar results have been reported by several other researchers [9-12]. In addition, three-dimensional numerical simulation conducted by Yilmaz and Unlu [13] showed that the anisotropy of the tensile failure zone of the blasting crater becomes larger when the differences between two principal stresses increase. Xie et al. [14] investigated the damage evolution process of deep rock during cut blasting, and the results showed that the damage zone decreases with the increase of in situ stresses. Yi et al. [15] studied the effect of levels and states of in situ stresses in rock on blasting damage evolution. Previous studies indicated that in situ stress has a large effect on the propagation of blasting-induced cracks as well as on the shape and size of failure zones. However, the existing studies are mostly limited to laboratory testing and numerical simulation and have seldom been applied in engineering practice. As a result, blasting efficiency can hardly be controlled in deep mining. 
Specific charges comprise a major index for blast design and assessment. Higher explosive consumption will lead to overbreak, while lower explosive consumption will lead to underbreak $[16,17]$. Moreover, the specific charge also affects the fragmentation of blasting. Kuznetsov [18] established a quantitative relationship model between the specific charge and fragmentation size distribution. The simulation results of Cho and Kaneko [19] show that higher specific charge leads to smaller fragmentation size. Experiments by Zhou et al. [20] and Li et al. [21] showed that the tensile strength and spall strength of rock decreases with increasing static prestresses, which means that high-stress rock excavation requires fewer explosives. It can be seen that the specific charge is closely related to the scope of the blasting damage zone, the blasting profile, the fragmentation size, and so on. Reasonable specific charges can not only improve blasting quality but can also reduce blasting cost.

In this study, the effect of stress loading on the specific charge is investigated using laboratory tests, and a design method for specific charges with the consideration of field stress is proposed. The design method is then applied to mining at China's Hongtoushan Copper Mine.

\section{Model Tests on Effect of Stress Loading on Specific Charge}

2.1. Test Condition. Results from explosion-crater tests are the basis for determining the design parameters of blast holes [22-25]. In blasting experiments on cement specimens, a qualitative model is mainly used. All model test blocks adopt the same parameters and specifications, and the failure law of the blasting process is studied through the difference analysis of blasting effect under different stress combination conditions. Cement specimens with a dimension of $200 \mathrm{~mm} \times 200 \mathrm{~mm} \times 150 \mathrm{~mm}$ were used for the crater blasting tests (Figures 1 and 2). The uniaxial compressive strength and density of the test material are $25.0 \mathrm{MPa}$ and $2143 \mathrm{~kg} / \mathrm{m}^{3}$, respectively.

The blasting parameters and stress loading conditions are shown in Figure 2. Static stresses were applied on the two side faces $(200 \mathrm{~mm} \times 150 \mathrm{~mm})$ of the specimen by a hydraulic loading device before detonation, as shown in Figure 2(a). The explosion model is described by the Cartesian coordinate system $(x, y, z)$, where the $x, y$, and $z$ directions correspond, respectively, to the maximum compressive stress direction, minimum compressive stress direction, and normal direction of the free surface. The stresses on the two side faces of the specimen are expressed as

$$
\begin{aligned}
& \sigma_{x}=\sigma_{0}, \\
& \sigma_{y}=\lambda \sigma_{0},
\end{aligned}
$$

where $\sigma_{x}$ and $\sigma_{y}$ are the normal stresses acting on the boundaries, $\lambda$ is the lateral stress coefficient $(0 \leq \lambda \leq 1)$, and $\sigma_{0}$ is a constant defining the stress magnitude.

A normalized variable, i.e., the stress-to-strength ratio, is introduced to represent the stress level, which has the form

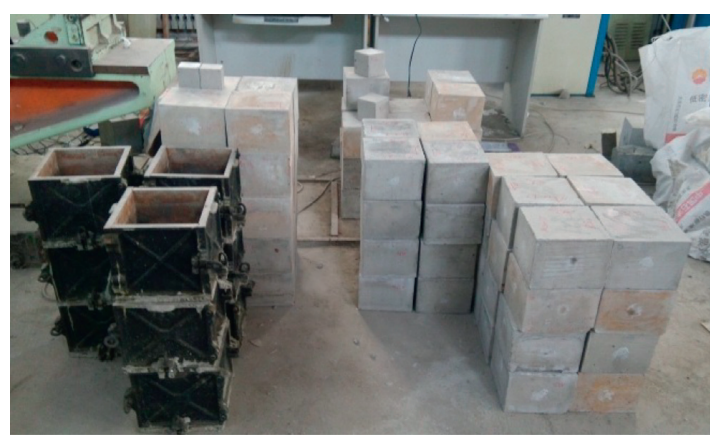

Figure 1: Cement specimens.

$$
\bar{\sigma}=\frac{\sigma_{0}}{\sigma_{c}},
$$

where $\sigma_{c}$ is the uniaxial compressive strength.

Using equation (2), equation (1) can be expressed in terms of $\bar{\sigma}$ as

$$
\begin{aligned}
\sigma_{x} & =\bar{\sigma} \sigma_{c}, \\
\sigma_{y} & =\lambda \bar{\sigma} \sigma_{c} .
\end{aligned}
$$

The blast hole, with a diameter of $8 \mathrm{~mm}$, was located on the center line of the $200 \mathrm{~mm} \times 200 \mathrm{~mm}$ surface. The bottom of the hole was $20 \mathrm{~mm}$ from the free surface (Figure 2(a)). The charge quantity remained constant at $500 \mathrm{mg}$ for each blast, with a charge height of $8 \mathrm{~mm}$, density of $1.24 \mathrm{mg} / \mathrm{mm}^{3}$, and a least-resistance line of $w=24 \mathrm{~mm}$ (Figure 2(b)). The explosives were composed of RDX (cyclotrimethylene trinitramine) and detonating explosives at a mixture ratio of 1 : 1 (Figure 3(a)). The blasting equipment included a fuse head and capacitive detonator (Figures 3(b) and 3(c)).

\subsection{Explosion Crater Shape under Different Stress Loading} Conditions. Taking the cases of $\lambda=0$ and $\lambda=1$ as examples, the effects of stress on the explosion-crater shape and specific charge are discussed. Figure 4 presents the explosion-crater shape under different stress loading conditions. The results indicate that the crater on the free surface is roughly circular when no lateral stress is applied (Figure 4(a)). When confining stresses are applied on the side faces, the explosion crater tends to be elliptical and the direction of the long axis of the crater is in the same direction of the lateral stress (Figures 4(b) and 4(c)). This indicates that the direction of major principal stress is the primary direction of failure propagation. Under an equal biaxial stress state, the failure zone is again circular due to the symmetry of stress loading conditions (Figures $4(\mathrm{~d})-4(\mathrm{f})$ ), which is similar to the case without any stress.

To more significantly describe the morphology of the explosion crater under different stress states, the morphology diagram of an explosion crater under different stress states was drawn according to the explosion-crater results in the field. As can be seen from Figure 5, when $\lambda=0$, the elliptical area increases with the increase in $\bar{\sigma}$, and the direction of the long axis increases significantly. When $\lambda=1$, the shape of the explosion crater is round. When 


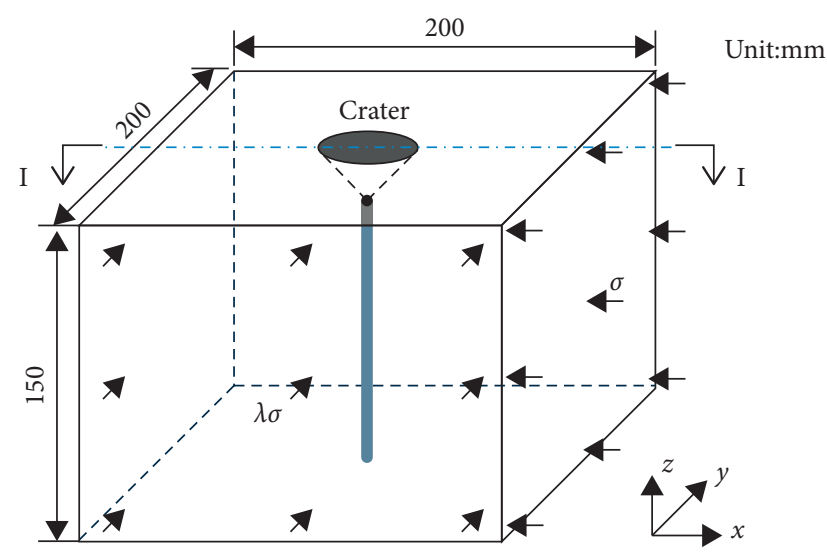

(a)
I - I

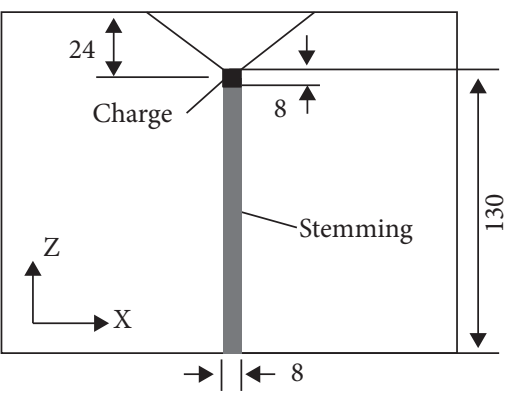

(b)

Figure 2: Geometric parameters of specimen and loading and charging conditions (units of mm): (a) test model; (b) cross section I-I.

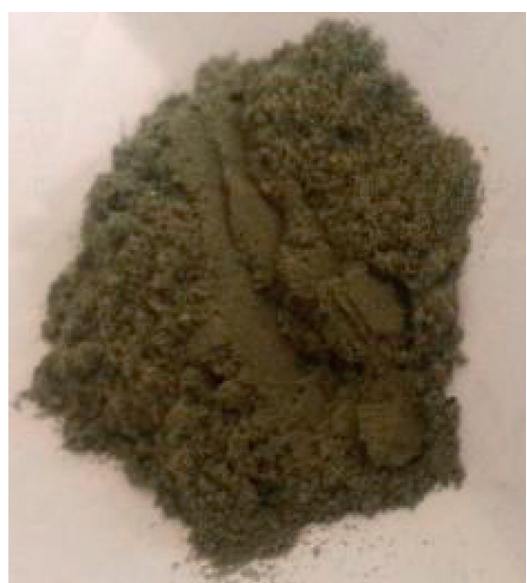

(a)

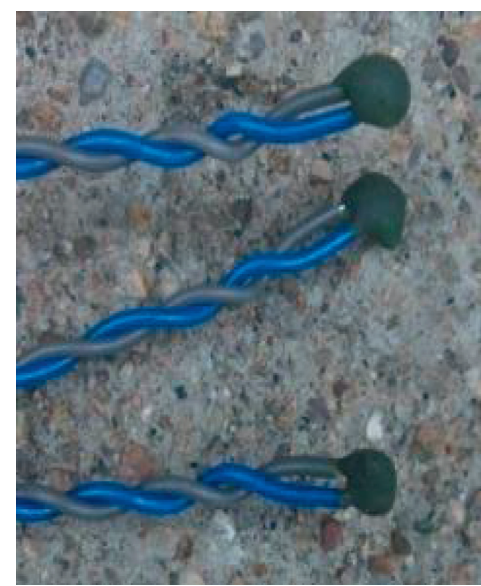

(b)

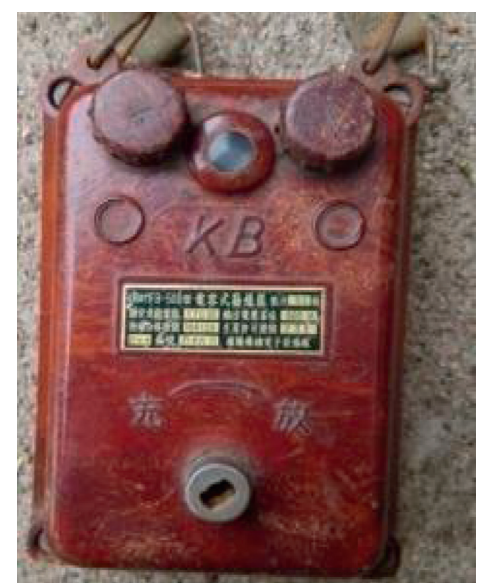

(c)

Figure 3: Explosives and blasting equipment: (a) mixed explosives; (b) fuse head; (c) capacitive detonator.

$\bar{\sigma}=0.2-0.25$, the explosion-crater area increases with increasing $\bar{\sigma}$. When $\bar{\sigma}=0.3$, the boundary of the specimen has been exceeded, indicating that the biaxial static stress has a more significant effect on blasting failure. The results show that the stress state of rock mass is one of the main factors influencing blasting rock fragmentation. The blasting design can be matched with the stress state of rock mass, and then, the blasting rock-breaking effect can be improved.

2.3. Variation of Specific Charge with Static Stress. Specific charge is defined as the amount of explosives required for blasting a unit mass of rock and can be described by the following equation:

$$
q=\frac{Q_{e}}{Q_{b}}
$$

where $q$ is the specific charge in $\mathrm{kg} / t, Q_{e}$ is the amount of explosive consumption in $\mathrm{kg}$, and $Q_{b}$ is the amount of rock blasted in $t$.
During the blasting tests, the explosive charge was $Q_{e}=500 \mathrm{mg}$ and the amount of rock blasted, $Q_{b}$, was determined by the following equation:

$$
Q_{b}=\rho V_{c r},
$$

where $\rho$ is the density of cement mortar and $V_{\mathrm{cr}}$ is the volume of the explosion crater.

To investigate the variation of specific charge with the lateral stress, the volume of the explosion crater was measured. The amount of rock blasted was calculated by equation (5), and then, the specific charge (in units of $\mathrm{mg} / \mathrm{g}$ ) was determined by equation (4). The variations of specific charge under different stress states were obtained and are shown in Figure 6.

It can be seen that the variations of specific charge are different under the two stress states of $\lambda=0$ and $\lambda=1$. With the same explosive charge and resistance line, uniaxial stress promotes specimen fragmentation under blasting. With increasing stress, the specific charge decreases gradually. However, under equal biaxial stress loading, the specific 


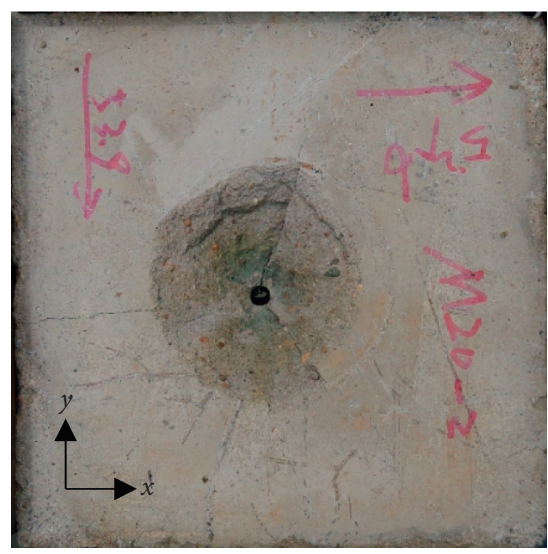

(a)

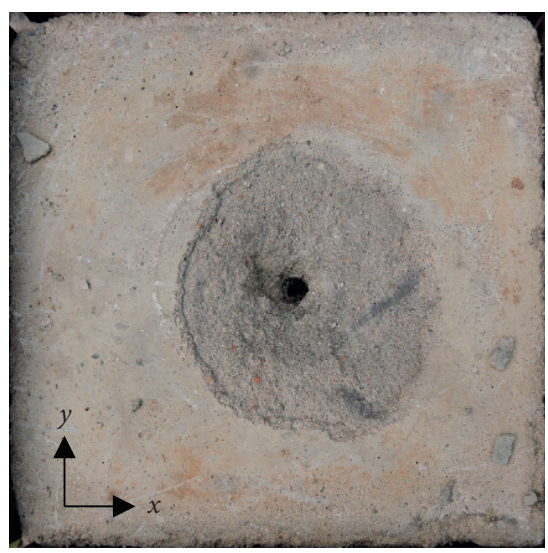

(d)

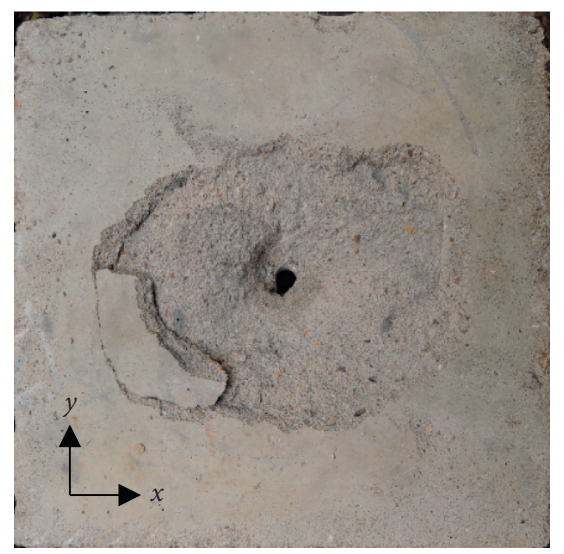

(b)

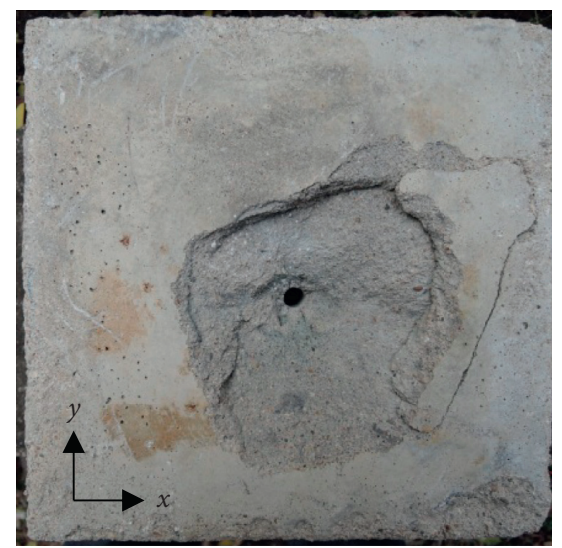

(e)

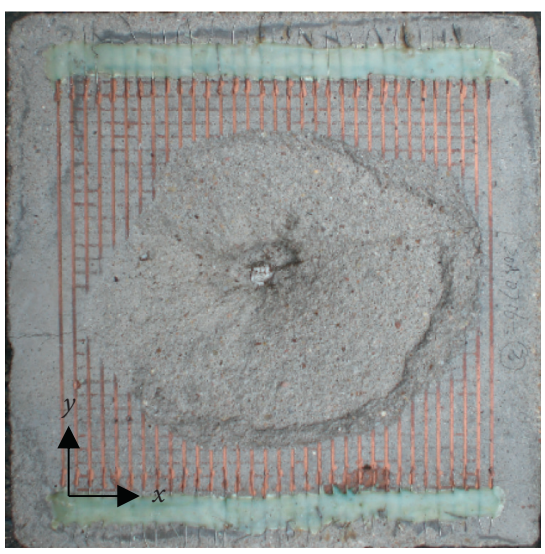

(c)

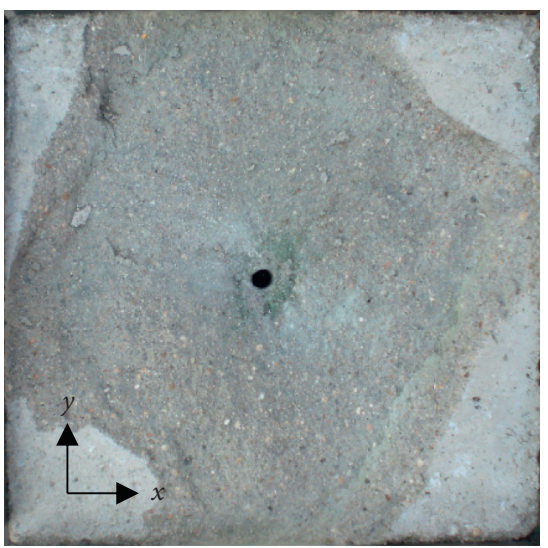

(f)

Figure 4: Shapes of craters under different lateral stresses: (a) $\bar{\sigma}=0, \lambda=0$; (b) $\bar{\sigma}=0.2, \lambda=0$; (c) $\bar{\sigma}=0.3, \lambda=0$; (d) $\bar{\sigma}=0.2, \lambda=1$; (e) $\bar{\sigma}=0.25, \lambda=1$; (f) $\bar{\sigma}=0.3, \lambda=1$.

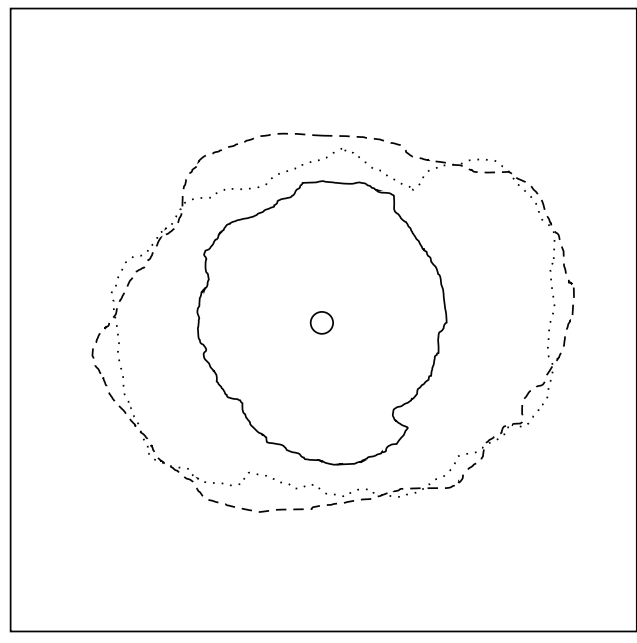

$$
\begin{aligned}
-\bar{\sigma} & =0, \lambda=0 \\
\cdots \cdots & \bar{\sigma}=0.2, \lambda=0 \\
--\bar{\sigma} & =0.3, \lambda=0
\end{aligned}
$$

(a)
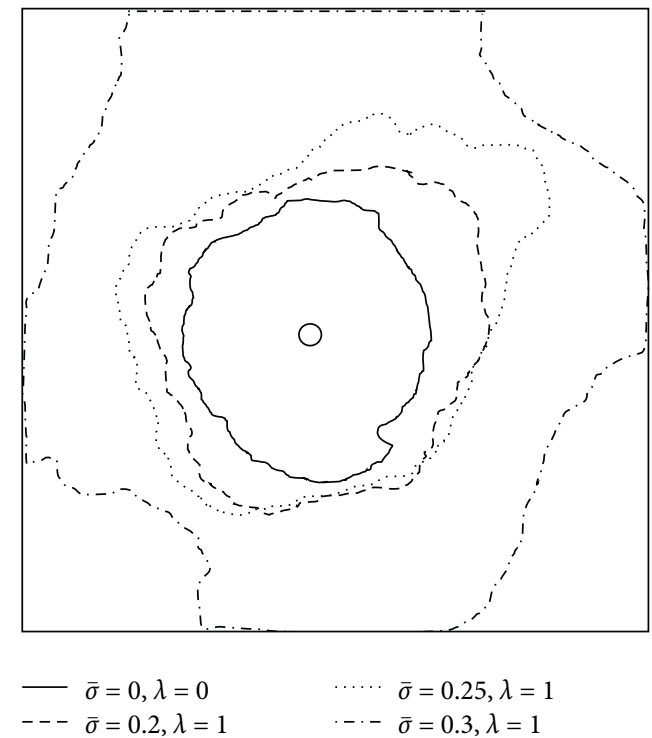

(b)

Figure 5: Schematic of explosion-crater shape under various static stresses: (a) $\lambda=0$; (b) $\lambda=1$. 


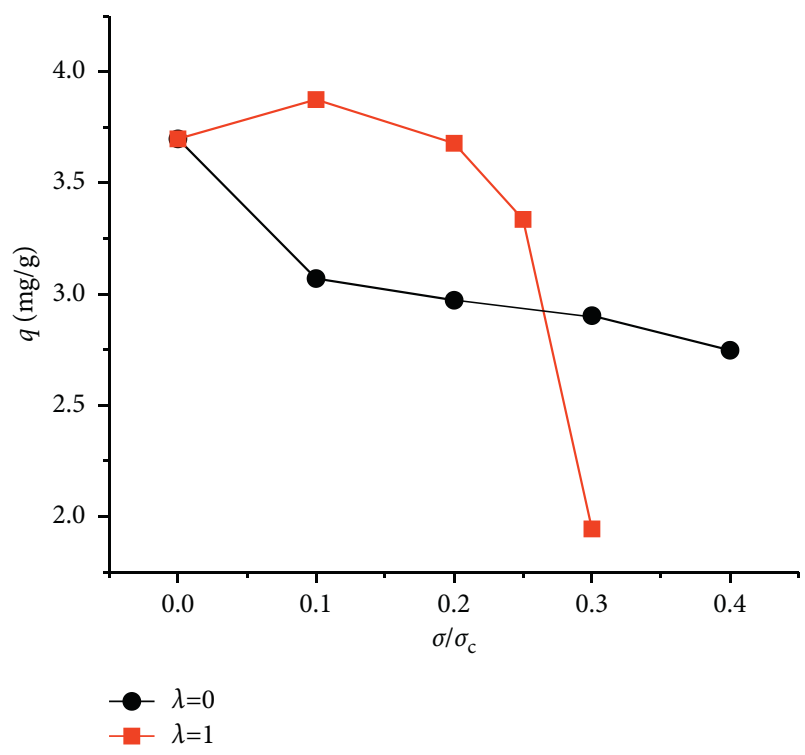

Figure 6: Variations of specific charge with static stress.

charge increases first and then decreases as the stresses increase, indicating that the biaxial stress first restrains and then promotes the formation of explosion craters. This role change occurs when the stress-to-strength ratio changes from $\bar{\sigma}=0.2$ to 0.25 . Thereafter, the specific charge decreases rapidly, indicating that rock fragmentation by blasting is easier under high equal biaxial stress loading. These results indicate that the stress-to-strength ratio of $\bar{\sigma}$ and the lateral stress coefficient $\lambda$ are two important parameters that influence specific charge.

2.4. Correction Coefficient for Specific Charge. It is shown from the above analysis that the specific charge can be determined based on the stress-to-strength ratio $\bar{\sigma}$ and lateral stress coefficient $\lambda$. In this study, a correction coefficient, which is a function of the stress-to-strength ratio $\bar{\sigma}$ and lateral stress coefficient $\lambda$, is introduced to consider the effect of stress on specific charge. The specific charge after correction can be expressed as

$$
q(\bar{\sigma}, \lambda)=\left(1+\delta_{q}(\bar{\sigma}, \lambda)\right) q_{0}
$$

where $q_{0}$ is the specific charge without stress loading, $q(\bar{\sigma}, \lambda)$ is the specific charge under high stress loading, and $\delta_{q}(\bar{\sigma}, \lambda)$ is the correction coefficient, which can be determined from the following equation:

$$
\delta_{q}(\bar{\sigma}, \lambda)=\frac{q(\bar{\sigma}, \lambda)-q_{0}}{q_{0}} .
$$

The correction coefficient corresponding to $\lambda=0$ and $\lambda=1$ can be calculated using equation (7), and the result is shown in Figure 7.

It can be seen that the variation trend of the unit consumption correction coefficient of explosives under two different stress states is obviously different. It is shown that the lateral pressure coefficient has a great effect on the unit consumption correction coefficient of explosives. In the case

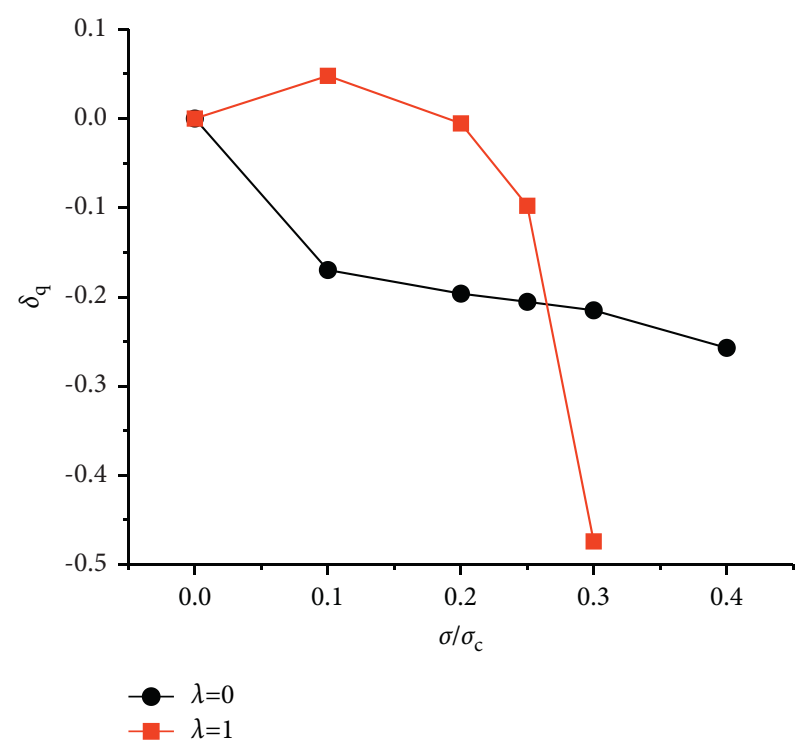

FIGURE 7: Variation of correction coefficient for specific charge with the stress-to-strength ratio.

of the same charge and resistance line, the unit consumption correction factor will decrease rapidly when the stress value changes from 0 to 0.1 , and it will decrease slowly with increasing pressure value after the stress value exceeds 0.1 . With increasing biaxial equivalent compressive stress, the unit consumption correction coefficient of explosive first increases and then slowly decreases. After the pressure value exceeds 0.25 , there is a period of sharp decline. This phenomenon is in contrast with that shown in Figures 4(d)-4(f).

In Table $1, \lambda$ is in the range 0 to 1 during mining. Therefore, a large number of test or numerical simulations are required to obtain $\delta_{q}(\bar{\sigma}, \lambda)$ under different stress states. In this paper, $\delta_{q}(\bar{\sigma}, \lambda)$ was obtained using interpolation between $\delta_{q}(\bar{\sigma}, 0)$ and $\delta_{q}(\bar{\sigma}, 1)$, and the results are shown in Table 1 . In the table, the results corresponding to $\lambda=0$ and $\lambda=1$ were obtained from the laboratory tests, and the other values were obtained based on linear interpolation between the test results. When $\bar{\sigma}>0.3, \delta_{q}(\bar{\sigma}, \lambda)$ values corresponding to $\bar{\sigma}=0.3$ are suggested.

\section{Blast Design considering In Situ Stress Field and Its Heterogeneity}

The test results from this study and the numerical simulation results from other studies $[14,15,26]$ indicate that the stress state changes the shape and range of blasting-induced failure zones and influences blasting efficiency. In this section, a blast design method considering the in situ stress field and its heterogeneity is proposed for mining in depth; the method is based on the corrected specific charge discussed above. The blasting design method is based on the following basic assumptions: (a) the rock mass is an ideal elastomer and (b) multirow porous blasting is the superposition of single-hole blasting action.

The stress distribution in a rock mass is heterogeneous and continuously evolves during mining. The stress field 
TABLE 1: Correction coefficients for specific charge under different stress states.

\begin{tabular}{lcccccccccccc}
\hline $\bar{\sigma}$ & & & \multicolumn{9}{c}{$\lambda$} & \multicolumn{1}{c}{ } \\
& 0 & 0.1 & 0.2 & 0.3 & 0.4 & 0.5 & 0.6 & 0.7 & 0.8 & 0.9 & 1 \\
\hline 0 & 0 & 0 & 0 & 0 & 0 & 0 & 0 & 0 & 0 & 0 \\
0.1 & -0.17 & -0.149 & -0.127 & -0.106 & -0.084 & -0.063 & -0.041 & -0.020 & 0.002 & 0.024 & 0.045 \\
0.2 & -0.209 & -0.189 & -0.169 & -0.149 & -0.129 & -0.109 & -0.088 & -0.068 & -0.048 & -0.028 & -0.008 \\
0.25 & -0.21 & -0.199 & -0.188 & -0.177 & -0.166 & -0.155 & -0.144 & -0.133 & -0.122 & -0.111 & -0.1 \\
0.3 & -0.211 & -0.238 & -0.264 & -0.291 & -0.317 & -0.344 & -0.370 & -0.397 & -0.423 & -0.450 & -0.476 \\
\hline
\end{tabular}

around each blast hole varies, and it is better to design the specific charge for each blast hole according to the stress field to increase blasting efficiency. However, this method involves a large amount of work and can hardly be implemented in practice. To simplify the blast design, an orebody is divided into zones with approximately uniform stress in each zone. The correction coefficient $\delta_{q}(\bar{\sigma}, \lambda)$ for a specific charge can then be determined according to the average stress-to-strength ratio $\bar{\sigma}_{a}$ and the average lateral stress coefficient $\lambda_{a}$ from the following equations:

$$
\begin{aligned}
& \bar{\sigma}_{a}=\frac{\int_{V} \bar{\sigma} \mathrm{d} V}{V}, \\
& \lambda_{a}=\frac{\int_{V} \lambda \mathrm{d} V}{V},
\end{aligned}
$$

where $V$ is the volume of rock in a zone.

The design procedures are as follows:

(1) The stress distribution in the orebody during mining is obtained by field measurement and back analysis using numerical simulation. The orebody is preliminarily divided into zones with approximately equal stresses.

(2) $\bar{\sigma}_{a}$ and $\lambda_{a}$ for each zone are calculated using equation $(8)$, and the correction coefficient $\delta_{q}(\bar{\sigma}, \lambda)$ is determined according to Table 1.

(3) The specific charge $q\left(\bar{\sigma}_{a}, \lambda_{a}\right)$ for each zone is calculated using equation (6).

(4) The blast design parameters can be determined according to the corrected specific charge.

\section{Engineering Applications}

4.1. Test Mine and Mining Area. Fushun Hongtoushan Copper Mine of the China Nonferrous Metal Mining (Group) Co. Ltd. was selected to test the blast design method considering the influence of stress field. The ore vein extends for more than $2000 \mathrm{~m}$ below the ground surface and the mine is one of the deepest metal mines in China with an annual output of $600,000 t$. Both horizontal adits and vertical shafts were constructed for mining. The original blast design scheme was established based on past experience, with some adjustments to the conditions encountered at the mine site. A lack of systematic study on improving blasting efficiency has existed in the past, leading to a poor ore dilution rate and loss rate. At the same time, the strong brittleness of rock mass frequently leads to the phenomenon of rockburst $[27,28]$.
In this study, field blasting experiments were conducted based on the corrected specific charge. As shown in Figure 8, the test field was located in a mining area 1077 to $1137 \mathrm{~m}$ ( -647 to $-707 \mathrm{~m}$ ) below the ground surface; the mining area was $28 \mathrm{~m}$ long, $17 \mathrm{~m}$ wide, and $60 \mathrm{~m}$ high [29]. Sublevel stoping was adopted as the mining method. The thicknesses of the roof and sill pillars were 8 and $10 \mathrm{~m}$, respectively. The medium-length hole caving method was adopted. Three layers of fan-shaped blast holes were drilled with a layer thickness of $14 \mathrm{~m}$. The orebody is copper-zinc ore, the surrounding rock mass is gneiss, and the material parameters are listed in Table 2.

4.2. In Situ Stress Field and Correction Coefficient for Specific Charge during Mining. The magnitudes and directions of the principal stresses in the rock masses were measured using the borehole stress relief method $[30,31]$, and the results are

(i) $\sigma_{1}=34.02 \mathrm{MPa}, \quad l_{1}=-0.426, \quad m_{1}=0.858, \quad$ and $n_{1}=-0.286$

(ii) $\sigma_{2}=16.48 \mathrm{MPa}, l_{2}=0.712, m_{2}=0.478$, and $n_{2}=0.515$

(iii) $\sigma_{3}=4.28 \mathrm{MPa}, \quad l_{3}=-0.580, m_{3}=-0.015, \quad$ and $n_{3}=0.815$

$\sigma_{1}, \sigma_{2}$, and $\sigma_{3}$ are the maximum principal stress, second principal stress, and minimum principal stress, respectively; $l_{\mathrm{i}}, m_{\mathrm{i}}$, and $n_{\mathrm{i}}$ are the cosines of $\sigma_{i}$ to the $x, y$, and $z$ axis directions in the original coordinate system, respectively.

The borehole stress relief method can only give the stresses at the measurement locations, and the back-analysis method was used to obtain the stress distribution in the mining area $[32,33]$. The blasting zones and sequence are shown in Figure 8 . The average stress-to-strength ratio $\bar{\sigma}_{a}$ and average lateral stress coefficient $\lambda_{a}$ in each zone were obtained by equation (8). Finally, the correction coefficients for specific charge in each zone were determined as listed in Table 1 and the results are listed in Table 3.

4.3. Results. During mining, slots were first drilled to provide free surfaces and compensation space for subsequent large-scale blasting. Blasting was then conducted from Zones I to $\mathrm{V}$. Ores and rocks were collected by the bottom structure after each caving zone, which provided compensation space for subsequent blasting. The numbers of blast holes and explosive consumptions in the original and revised designs based on the proposed method are listed in Tables 4 and 5, respectively. It can be seen that, using the proposed blasting scheme, the number of blast holes in the test area decreased 


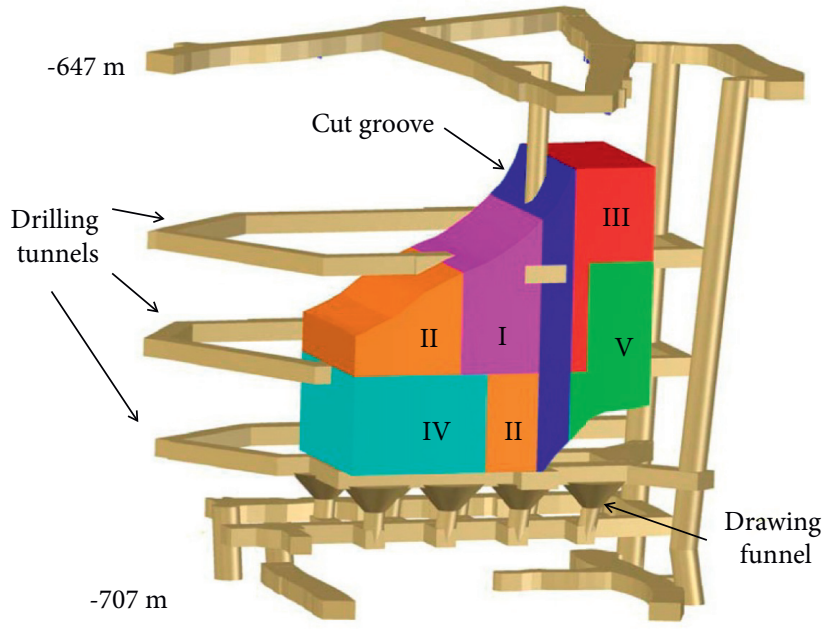

Figure 8: Layout of the mining area [29].

TABLE 2: Material property parameters.

\begin{tabular}{lccccc}
\hline Lithology & Uniaxial compressive strength $(\mathrm{MPa})$ & Elastic modulus $(\mathrm{GPa})$ & Poisson's ratio & Cohesion $(\mathrm{MPa})$ & Friction angle $\left(^{\circ}\right)$ \\
\hline Gneiss & 139.0 & 63 & 0.26 & 10.23 & 40.81 \\
Copper-zinc ore & 95.0 & 56 & 0.29 & 6.91 & 40.47 \\
\hline
\end{tabular}

TABLE 3: Correction coefficients for specific charge under different stress conditions.

\begin{tabular}{lcccc}
\hline Blasting zone & Zone I & Zone II & Zone III & Zone IV \\
\hline Stress-to-strength ratio, $\bar{\sigma}_{a}$ & 0.297 & 0.329 & 0.348 & 0.244 \\
Lateral stress coefficient, $\lambda_{a}$ & 0.325 & 0.345 & 0.277 & 0.242 \\
Correction coefficient for specific charge, $\delta_{q}$ & -0.291 & -0.300 & -0.243 & 0.396 \\
\hline
\end{tabular}

TABle 4: Drilling quantity comparison at Hongtoushan Copper Mine.

\begin{tabular}{|c|c|c|c|c|c|c|}
\hline \multirow{2}{*}{$\begin{array}{l}\text { Blasting } \\
\text { zone }\end{array}$} & \multicolumn{2}{|c|}{ Original parameters } & \multicolumn{2}{|c|}{ Test scheme } & \multirow{2}{*}{$\begin{array}{l}\text { Percentage reduction of no. } \\
\text { of blast holes }(\%)\end{array}$} & \multirow{2}{*}{$\begin{array}{c}\text { Percentage reduction of length } \\
\text { of blast holes }(\%)\end{array}$} \\
\hline & $\begin{array}{c}\text { No. of blast } \\
\text { holes }\end{array}$ & $\begin{array}{l}\text { Length of blast } \\
\text { holes }(\mathrm{m})\end{array}$ & $\begin{array}{l}\text { No. of blast } \\
\text { holes }\end{array}$ & $\begin{array}{l}\text { Length of blast } \\
\text { holes }(\mathrm{m})\end{array}$ & & \\
\hline I & 202 & 1655.6 & 161 & 1323.2 & 20.3 & 20.1 \\
\hline II & 254 & 1960.4 & 210 & 1635.4 & 17.3 & 16.6 \\
\hline III & 170 & 1527.4 & 146 & 1320.9 & 14.1 & 13.5 \\
\hline IV & 311 & 2558 & 255 & 2111 & 18.0 & 17.5 \\
\hline $\mathrm{V}$ & 254 & 2246.9 & 193 & 1736.9 & 24.0 & 22.7 \\
\hline Total & 1191 & 9948.3 & 965 & 8127.5 & 19.0 & 18.3 \\
\hline
\end{tabular}

TABle 5: Comparison of explosives at Hongtoushan Copper Mine.

\begin{tabular}{lccc}
\hline Blasting zone & Explosives saved $(\mathrm{kg})$ & Percentage reduction of explosives $(\%)$ & Theoretical correction coefficient for specific charge, $\delta_{q}(\%)$ \\
\hline I & 447.0 & 20.1 & 29.1 \\
II & 427.4 & 18.4 & 30.0 \\
III & 281.3 & 13.0 & 24.3 \\
IV & 599.0 & 19.2 & 27.6 \\
V & 690.5 & 27.7 & 27.5 \\
Total & 2445.2 & 19.8 & 27.7 \\
\hline
\end{tabular}

from 1,191 to 965 , accounting for $19.0 \%$ of the number of original holes. The drilling length was reduced to $1820.8 \mathrm{~m}$ and the explosive unit consumption decreased by $19.8 \%$. Meanwhile, the blasting boundary was well controlled.
It should be noted that the actual specific charge in the test field was only reduced by $19.8 \%$, while the theoretical average specific charge obtained by calculation was reduced by $27.2 \%$. The theoretical correction coefficient for specific 
charge was calculated based on the laboratory test results in combination with the in situ stress field. The lithology and blasting conditions were different from those in the test field. Therefore, the correction coefficients for specific charge in various zones adopted in the field tests were smaller than the theoretical values.

\section{Conclusions}

The conclusions of this study can be summarized as follows.

The stress loading condition has a large influence on specific charge. Under the uniaxial stress state, the stress field promotes rock fragmentation, and the specific charge decreases with increasing stress magnitude. Under the equal biaxial stress state, the specific charge first increases and then decreases rapidly as the stress-to-strength ratio increases.

A design method for specific charge, considering the influence of field stress in underground mines, is proposed. The stress distribution in the blasting area is obtained first. The blasting area is preliminarily divided into zones with approximately equal stress in each zone. The average stressto-strength ratio and average lateral stress coefficient are then calculated for each zone. The correction coefficient and specific charge are determined. The corrected specific charge can be applied to the blast design. The blasting test results at Hongtoushan Copper Mine indicate that drilling and blasting workload can be reduced significantly, as the actual specific charge was reduced by $19.8 \%$.

\section{Data Availability}

The data used to support the findings of this study are available from the corresponding author upon request.

\section{Conflicts of Interest}

The authors declare that they have no conflicts of interest.

\section{Acknowledgments}

This research was supported financially by the State Key Research Development Program of China (2017YFC0602902). The authors thank Accdon (https:// www.accdon.com) for its linguistic assistance during the preparation of this manuscript.

\section{References}

[1] P. N. Neingo and T. Tholana, "Trends in productivity in the South African gold mining industry," Journal of the South African Institute of Mining and Metallurgy, vol. 116, no. 3, pp. 283-290, 2016.

[2] E. T. Brown and E. Hoek, "Trends in relationships between measured in-situ stresses and depth," International Journal of Rock Mechanics and Mining Science \& Geomechanics Abstracts, vol. 15, no. 4, pp. 211-215, 1978.

[3] C. Chunlin Li, "A new energy-absorbing bolt for rock support in high stress rock masses," International Journal of Rock Mechanics and Mining Sciences, vol. 47, no. 3, pp. 396-404, 2010.
[4] A. Mazaira and P. Konicek, "Intense rockburst impacts in deep underground construction and their prevention," $\mathrm{Ca}$ nadian Geotechnical Journal, vol. 52, no. 10, pp. 1426-1439, 2015.

[5] Y. Z. Yang, Z. S. Shao, J. F. Mi, and X. F. Xiong, "Effect of adjacent hole on the blast-induced stress concentration in rock blasting," Advances in Civil Engineering, vol. 2018, Article ID 5172878, 2018.

[6] B. B. Chen and C. Y. Liu, "Analysis and application on controlling thick hard roof caving with deep-hole position presplitting blasting," Advances in Civil Engineering, vol. 2018, Article ID 9763137, 2018.

[7] L. X. Xie, W. B. Lu, J. C. Gu, and G. H. Wang, "Excavation method of reducing blasting vibration in complicated geological conditions," Shock and Vibration, vol. 2018, Article ID 2518209, 2018.

[8] H. K. Kutter and C. Fairhurst, "On the fracture process in blasting," International Journal of Rock Mechanics and Mining Science \& Geomechanics Abstracts, vol. 8, no. 3, pp. 181-202, 1971.

[9] F. V. Donzé, J. Bouchez, and S. A. Magnier, "Modeling fractures in rock blasting," International Journal of Rock Mechanics and Mining Sciences, vol. 34, no. 8, pp. 1153-1163, 1997.

[10] W. J. Jung, M. Utagava, Y. Ogata, and M. Seto, "Effects of rock pressure on crack generation during tunnel blasting," Journal of the Japan Explosives Society, vol. 62, no. 3, pp. 138-146, 2001.

[11] G. W. Ma and X. M. An, "Numerical simulation of blastinginduced rock fractures," International Journal of Rock Mechanics and Mining Sciences, vol. 45, no. 6, pp. 966-975, 2008.

[12] L.-Y. Yang and C.-X. Ding, "Fracture mechanism due to blastimposed loading under high static stress conditions," International Journal of Rock Mechanics and Mining Sciences, vol. 107, pp. 150-158, 2018.

[13] O. Yilmaz and T. Unlu, "Three dimensional numerical rock damage analysis under blasting load," Tunnelling and Underground Space Technology, vol. 38, pp. 266-278, 2013.

[14] L. X. Xie, W. B. Lu, Q. B. Zhang, Q. H. Jiang, G. H. Wang, and J. Zhao, "Damage evolution mechanisms of rock in deep tunnels induced by cut blasting," Tunnelling and Underground Space Technology, vol. 58, pp. 257-270, 2016.

[15] C. Yi, D. Johansson, and J. Greberg, "Effects of in-situ stresses on the fracturing of rock by blasting," Computers and Geotechnics, vol. 104, pp. 321-330, 2018.

[16] J. A. Ibarra, N. H. Maerz, and J. A. Franklin, "Overbreak and underbreak in underground openings part 2: causes and implications," Geotechnical \& Geological Engineering, vol. 14, no. 4, pp. 325-340, 1996.

[17] L. An, F. T. Suorineni, S. Xu, Y.-H. Li, and Z.-C. Wang, "A feasibility study on confinement effect on blasting performance in narrow vein mining through numerical modelling," International Journal of Rock Mechanics and Mining Sciences, vol. 112, pp. 84-94, 2018.

[18] V. M. Kuznetsov, "The mean diameter of the fragments formed by blasting rock," Soviet Mining Science, vol. 9, no. 2, pp. 144-148, 1973.

[19] S. H. Cho and K. Kaneko, "Rock fragmentation control in blasting," Materials Transactions, vol. 45, no. 5, pp. 1722-1730, 2004.

[20] Z. Zhou, X. Li, Y. Zou, Y. Jiang, and G. Li, "Dynamic Brazilian tests of granite under coupled static and dynamic loads," Rock Mechanics and Rock Engineering, vol. 47, no. 2, pp. 495-505, 2014. 
[21] X. Li, M. Tao, C. Wu, K. Du, and Q. Wu, "Spalling strength of rock under different static pre-confining pressures," International Journal of Impact Engineering, vol. 99, pp. 69-74, 2017.

[22] W. L. Fourney, R. D. Dick, X. J. Wang, and Y. Wei, "Fragmentation mechanism in crater blasting," International Journal of Rock Mechanics and Mining Science \& Geomechanics Abstracts, vol. 30, no. 4, pp. 413-429, 1993.

[23] Z. M. Zhu, "Numerical prediction of crater blasting and bench blasting," International Journal of Rock Mechanics and Mining Sciences, vol. 6, no. 46, pp. 1088-1096, 2009.

[24] X. Qiu, X. Shi, Y. Gou, J. Zhou, H. Chen, and X. Huo, "Shortdelay blasting with single free surface: results of experimental tests," Tunnelling and Underground Space Technology, vol. 74, pp. 119-130, 2018.

[25] F. Zhang, J. Peng, Z. Qiu, Q. Chen, Y. Li, and J. Liu, "Rock-like brittle material fragmentation under coupled static stress and spherical charge explosion," Engineering Geology, vol. 220, pp. 266-273, 2017.

[26] L. X. Xie, W. B. Lu, Q. B. Zhang, Q. H. Jiang, M. Chen, and J. Zhao, "Analysis of damage mechanisms and optimization of cut blasting design under high in-situ stresses," Tunnelling and Underground Space Technology, vol. 66, pp. 19-33, 2017.

[27] L. Dong, J. Wang, X. Li, and K. Peng, "Dynamic stability analysis of rockmass: a review," Advances in Civil Engineering, vol. 2018, Article ID 4270187, 22 pages, 2018.

[28] Y. H. Zhang, J. Ma, D. Y. Sun et al., "AE characteristics of rockburst tendency for granite influenced by water under uniaxial loading," Frontiers of Earth Science, vol. 8, pp. 1-12, 2020.

[29] J.-p. Liu, S.-d. Xu, Y.-h. Li, and G. Lei, "Analysis of rock mass stability based on mining-induced seismicity: a case study at the hongtoushan copper mine in China," Rock Mechanics and Rock Engineering, vol. 52, no. 1, pp. 265-276, 2019.

[30] C. Ljunggren, Y. Chang, T. Janson, and R. Christiansson, “An overview of rock stress measurement methods," International Journal of Rock Mechanics and Mining Sciences, vol. 40, no. 78, pp. 975-989, 2003.

[31] F. Zhang, Z. Qiu, and X. Feng, "Non-complete relief method for measuring surface stresses in surrounding rocks," Journal of Central South University, vol. 21, no. 9, pp. 3665-3673, 2014.

[32] C. X. Yang, Y. H. Wu, T. Hon, and X.-T. Feng, “Application of extended Kalman filter to back analysis of the natural stress state accounting for measuring uncertainties," International Journal for Numerical and Analytical Methods in Geomechanics, vol. 35, no. 6, pp. 694-712, 2011.

[33] C. X. Yang, Y. F. Zhu, Y. H. Wu, and S. Xu, "Optimized backanalysis of regional tectonic stress based on genetic algorithms," Disaster Advances, vol. 5, no. 4, pp. 1581-1587, 2012. 